\title{
Transatlantica
}

Revue d'études américaines. American Studies Journal

Time-Images in Don DeLillo's Writing: A Reading of The Body Artist, Point Omega and Zero K

\section{Andrea Pitozzi}

\section{(2) OpenEdition}

Journals

Electronic version

URL: https://journals.openedition.org/transatlantica/15751

DOI: $10.4000 /$ transatlantica. 15751

ISSN: 1765-2766

\section{Publisher}

Association française d'Etudes Américaines (AFEA)

Electronic reference

Andrea Pitozzi, "Time-Images in Don DeLillo's Writing: A Reading of The Body Artist, Point Omega and Zero K", Transatlantica [Online], 1 | 2020, Online since 01 December 2020, connection on 01 February 2023. URL: http://journals.openedition.org/transatlantica/15751 ; DOI: https://doi.org/10.4000/ transatlantica. 15751

This text was automatically generated on 1 February 2023.

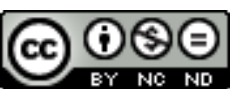

Creative Commons - Attribution-NonCommercial-NoDerivatives 4.0 International - CC BY-NC-ND 4.0 https://creativecommons.org/licenses/by-nc-nd/4.0/ 


\title{
Time-Images in Don DeLillo's Writing: A Reading of The Body Artist, Point Omega and Zero $K$
}

\author{
Andrea Pitozzi
}

Time is too difficult.

Don DeLillo, Zero K (68)

\section{In the Realm of Images}

1 In his writings Don DeLillo has always employed images as a powerful instrument providing an immediate access to post-World-War-II American culture. From the remarks on the world of media and cinema contained in his first novel Americana (1971) to the detailed descriptions of the video of Kennedy's assassination in Libra (1988), from discussions on photography and television in White Noise (1985) or Mao II (1991) to the constellation of photographs, movies and video frames haunting the pages of Underworld (1997), the writer has frequently selected iconic images from the twentieth century as a narrative basis. In many of the quoted examples, the images selected by DeLillo seem to be somehow pre-supposed, in that they act as a pre-text providing the narrative with a certain space of inquiry, where words claim a more authentic report of the events hidden behind and below the surface of the serialized reproduction of images themselves in the media culture. ${ }^{1}$ In other words, these images show a symptomatic function $^{2}$ and denote the problematic gap between reality and representation that DeLillo's writing tries to bring to light if not to fill. Moreover, this critical way of dealing with images, which somehow epitomizes the postmodernist position in regard to the contemporary mediatized society, is also one of the most significant topics chosen by many critics in order to demonstrate DeLillo's special place within the postmodern literary tradition. ${ }^{3}$

2 However, such an approach to the image seems to undergo a change in the novels DeLillo has written since Underworld, namely those published in the twenty-first 
century. In particular, The Body Artist (2001), Point Omega (2006) and Zero K (2016) all show a narrowing of the field of vision, and focus on the way images are experienced and perceived instead of concentrating on their de-realizing power or on their mystifying nature within a sort of ever reproduced reality, as it partially was the case with the previous works. In his post-millennial novels DeLillo's writing is more interested in representing the nature and reality of images themselves than in using them as a source for the narrative. Although it might be argued that such an approach is also present in Cosmopolis (2003), Falling Man (2007), as well as in the play Love-LiesBleeding (2005), what the three books I will study share is a more specific attention to the way characters perceive the world around them through images mixed up with their own intradiegetic reality. Moreover, besides the involvement with a conceptualization of the image through the narrative, The Body Artist, Point Omega and Zero $K$ also exemplify modalities of dealing with another key element in recent novels by DeLillo, that is time conceived of as a whole to be perceived and sensed. Time and image are thus interestingly entangled in the three novels, and present the reader with a perspective that seems to echo Gilles Deleuze's theorization of time in his works on cinema, as well as Henri Bergson's reasoning on the fundamental idea of duration.

My intention here is not to demonstrate that DeLillo's concern with time and images could possibly have been inspired by the philosophy of Deleuze or Bergson; rather, it is more interesting to see how recent fictions by DeLillo show a more reflective and meditative attitude towards themes that have always played a significant role in his narratives. ${ }^{4}$ To this extent, I aim to read The Body Artist, Point Omega and Zero $K$ in the light of concepts and notions I will draw from the philosophy of Bergson and Deleuze. On the one hand, in these three works the writing seems to question images more than just describe them. In taking images as their focus, DeLillo's narratives open to a new temporality that might be assimilated to the notion of a duration internal to the image itself and to the very moment of its perception: the narration becomes the place where images are re-created and no longer represented or repeated. On the other hand, the treatment of images within the novels affects the perception of time itself, as well as the narrative organization, by suspending the continuity of a story and introducing a multiplicity of different perspectives that integrate the subjective experience with an always other and mysterious reality and time scheme. In this sense, such a way of dealing with images and time is also reflected in DeLillo's use of a more speculative language that continuously suspends the action in order to make room for his characters' reflections and visions.

\section{Opening Images and Time to Perception}

The Body Artist, Point Omega and Zero $K$ are mainly composed of scenes and descriptions that isolate specific moments where characters are depicted in a sort of ecstatic contemplation of both the reality and its translation into images, on the same level. Instead of focusing on the dysfunctions derived from a bulimic consumption of televised images that hides the real core of events, DeLillo becomes more and more interested in showing the possibility of going deeper into the description of how these images are experienced, by looking into them, inquiring into their very structure, their grain, and finally their own reality and nature. In other words, more than just an ekphrastic description of the images circulating in the world, the writer increasingly 
concentrates on presenting the reader with scenes taking on an imaginal nature that also affects the temporal structure of the narrative.

What DeLillo describes is thus the reality of images, the very act of perception reconfigured into a sort of vision, his narrative becoming a way of writing-throughimages. In fact, while the presupposed image gave rise to an inherent separation between reality and representation, the reconfiguration of images into the narrative presents the reader with the experience of images as reality, and then as a possible form of presence, understood both in terms of something that is temporally and physically present. To put it differently, while the symptomatic image served as an input to the narrative reconfiguration of events and activated the potential counternarratives, in recent novels the image acquires a narrative substance in its own right, and merges entirely with reality into the perceptual life of characters who experience it as another reality intervening in (and becoming part of) their own world. Such a transition is also reflected in the temporal organization of the novels. Instead of being focused on what Peter Boxall refers to as a time "measured in decades," which is the kind of historical framework DeLillo points to by choosing iconic images in his premillennial works, the books under analysis seem to move towards an "unmeasured time," a "time which has lost its sense of identity" (Boxall, 2006 215). In this sense, we also witness a passage from a temporality established by "decade boundary, which both orients the prose, and works to contain it," to an "unframed" temporality, an "entry into the suspended non-time of posthistorical mourning [which] is also a delivery into the very fibrous material of the moment," as Boxall puts it (215-217). In works such as The Body Artist, Point Omega and Zero $K$, these moments are suspended and constitute new images that escape any possible function except that of conveying and suggesting a new temporality and a new way of seeing. In fact, moments of contemplation within the narrative are projected into a time that seems to slow down until it stops and stretches before the reader who, in turn, is asked to contemplate the emergence of an entirely new image, reconfigured by the narrative. A clear example is given in the first lines of The Body Artist, where DeLillo directly involves the reader in an act of perception:

Time seems to pass. The world happens, unrolling into moments, and you stop to glance at a spider pressed to its web. There is a quickness of light and a sense of things outlined precisely [...]. You know more surely who you are on a strong bright day after a storm when the smallest falling leaf is stabbed with self-awareness. The wind makes a sound in the pines and the world comes into being, irreversibly. (2001 7)

In this case, a disembodied narrative voice expresses the process of the world's "coming into being," which becomes itself an image involving a modification of time. On the other hand, although referring to an already mediated domain, even the first pages of Point Omega offer the reader a new perspective on time and vision, while presenting a character absorbed in the very act of looking at images: "The less there was to see, the harder he looked, the more he saw. This was the point. To see what's here, finally to look and to know you are looking, to feel time passing, to be alive to what is happening in the smallest registers of motion." (2010 6) Similar passages are very common in recent works by DeLillo, and perfectly illustrate a more reflective attitude, although they don't strictly belong to any specific or well-identified character. As a result, these parts might be thought of as images perceived and elaborated into narrative, and they configure a movement of the narration itself, a way of describing 
the smallest instants and the "subatomic" world around us. Thus, these parts might be considered as images open to multiple visions, fragments that affect the narrative time by privileging static figures in a contemplative attitude over movement and action.

6 From a strictly narratological point of view, such a way of describing moments of selfabsorption could be related to the narrative temporal organization expressed by Gérard Genette in Narrative Discourse: An Essay in Method (1972) while discussing the idea of duration that emerges from the analysis of Marcel Proust's writing. ${ }^{5}$ Among the forms of narrative movement (summary, pause, ellipsis, scene) examined by Genette, the one that best applies to DeLillo's cases is the pause, which designates the moment where story time almost suspends and narrative time focuses on descriptions. Genette then talks of an iterative quality of the pause-when time "is not connected to a particular moment in the story but to a series of analogous moments" (Genette 99)-in order to better explain the particular case of Proustian descriptions. Such a particular pause is "less a description of the object contemplated than it is a narrative and analysis of the perceptual activity of the character contemplating: of his impressions, progressive discoveries, shifts in distance and perspective, errors and corrections" (102). These words perfectly apply to the passages quoted above, and they could be referred to DeLillo's way of writing down the very thinking process of his characters. Thus, narrative suspension as Genette conceives it opens up the description of the character's inner contemplative attitude, and these pieces refer to the integration of different and separated times and moments recollected in the form of images.

The same idea of a composition of different times, and the consequent form of duration as a constant flux of several perceptions, finds a philosophical precedent in the thought of Henri Bergson, whose theories about subjective time had an extraordinary impact on the European modernist literature of early twentieth century. Needless to say, Bergson's thought influenced some of the most important writers of the time, from Marcel Proust himself to Virginia Woolf and T.S. Eliot, to mention but a few authors who tried to elaborate a literary equivalent of his ideas of time and consciousness. Nevertheless, what specifically interests us here about Bergson is the way he presents time itself as a form of materiality expressed through a complex idea of duration, and its future importance for the thought of French philosopher Gilles Deleuze. First of all, the idea of a "pure duration" provided Bergson with the possibility of recuperating a qualitative and subjective experience of time associated with consciousness and perception. In these terms, within the pages of Time and Free Will (1889), the philosopher conceived of duration as "a succession of qualitative changes, which melt into and permeate one another, without precise outlines" (Bergson, 2001 104). It is well known that Bergsonian time radically challenged any common idea of a measurable time understood as a line or a precise succession of minutes and hours. Instead, he proposed to regard time as a "pure heterogeneity" (104). Moreover, such heterogeneity is not just a pure abstraction of the mind, but it seems to acquire physicality through the acts of contemplation and perception. In fact, almost at the beginning of Matter and Memory (1896), Bergson wrote: "I call matter the aggregate of images, and perception of matter these same images referred to the eventual action of one particular image, my body" (Bergson, 2007 8).

8 The idea of a "pure duration," then, coincides with all the times and perceptions originated in a precise actual moment which is itself an image amidst images, and these images are nothing but the matter constituting the world, as well as the experience of 
this very world. The moment of perception also marks another essential aspect of Bergson's philosophy, namely the idea of "intuition" conceived of as a method of approaching reality, which corresponds to an internal flow of time. Thus, mental life is a flowing experience, and duration is the immediate awareness of this flow as it comes to mind. But in order to express the temporality implied in such an activity of perception-and the consequent idea of duration-Bergson had to introduce the material quality of the images, so as to give a physicality to time itself.

Therefore, in Bergson's thought, both the body that perceives images and the image of the perceiving body are on the same plane, they coexist in a similar flow or duration. In other words, there is a co-presence of both consciousness and the world; and according to the philosopher the two elements can be considered in terms of images marked by a material quality. This also means that memory itself is conceived of as matter, and not just as something deprived of any consistency: "it is a memory within change itself, a memory that prolongs the before into the after, keeping them from being mere snapshots appearing and disappearing in a present ceaselessly reborn" as Bergson himself puts it in Duration and Simultaneity (30). In this sense, duration came to be understood as a mass of time actualized and unleashed by the precise moment of perception.

\section{Towards a Time-Image}

Most pertinently for my approach here, Bergson's understanding of time and duration plays a central role in the thought of French philosopher Gilles Deleuze, and above all in his way of dealing with images and time as concepts immanent to reality itself. In Deleuze's reading of Bergson, duration is above all related to the fundamental idea of becoming. Instead of considering time as a simple succession of different moments, duration is thus a constant flow of one moment into the other in a continuous overlapping of images and of different times, giving rise to several forms of multiplicity. To put it differently, according to Deleuze, Bergson considers duration itself as a qualitative multiplicity that resides in the subject, as opposed to a numerical and objective multiplicity within the object itself conceived of as a series of actual divisions. As Deleuze puts it:

The subjective, or duration, is the virtual. To be more precise, it is the virtual insofar as it is actualized, in the course of being actualized, it is inseparable from the movement of its actualization. [...] A non-numerical multiplicity by which duration or subjectivity is defined, plunges into another dimension, which is no longer spatial and is purely temporal: it moves from the virtual to its actualization, it actualizes itself by creating lines of differentiation. (Deleuze, 1991 42-43)

Moreover, such a "movement of actualization" is at the basis of the action that memory exerts on the present, or, in other words, it is the way that the past affects the present by means of the coexistence of different times and images presented simultaneously. Deleuze here takes a further step towards the idea of "pure time" that will be a key concept leading to the notion of time-image as presented in the second volume of his work about cinema. In his reading of Bergson, he focuses on the notion of "pure recollection," which he considers an extra-psychological element. In fact, the present is psychological because it is where consciousness is, but for this very reason it is above all the activity of consciousness. As Deleuze wrote: 
The present is not; rather it is pure becoming always outside itself. It is not but it acts. Its proper element is not being but the active or the useful. The past, on the other hand, has ceased to act or to be useful. But it has not ceased to be. Useless and inactive, impassive, it is, in the full sense of the word: it is identical to being in itself. [...] it is the in-itself of being, and the form under which being is preserved in itself (Deleuze, 1991 55).

Thus, the past is always at hand, because it is and it exists per se. So, according to this view, memory is always a virtual coexistence on the verge of being actualized regardless of a specific subjectivity. In fact, Deleuze also seems to warn us against another possible confusion when he makes a distinction between the use of the word "unconscious" in Bergson and in Freud. In contrast to Freud's understanding of that notion as something inseparable from an effective psychological existence, "Bergson does not use the word 'unconscious' to denote a psychological reality outside consciousness, but to denote a nonpsychological reality-being as it is in itself' (56).

11 Such overcoming of the subject towards a state of co-existence between the actual conscious perception and the autonomous mass of the virtual past, as well as notions such as multiplicity, duration and movement, become central elements of Deleuze's approach to cinema and art in his latest works. In fact, in the two books devoted to the cinematographic image, Deleuze presents a philosophy of time that passes through a radical change in the understanding and reading of the image itself, which is no longer analysed in terms of representation or symbol, but comes to be understood as a reality in itself, provoking sensations: a "coalescence" of a series of images into an experimental and creative perspective. So, in his books on cinema, Deleuze explains the shift from an "image of time"-i.e. an image showing the passage of time through the representation of successive moments and movements-to what he calls a "direct timeimage": an image that displays pure time in itself. The first type of image is analysed in Cinema 1: The Movement-Image, and mainly concerns pre-World War II American cinema; while the second can be recognized in the examples quoted in Cinema 2: The Time-Image, which deals with cinematographic images considered as "primarily optical and of sound, invested by the senses" (Deleuze, 1997 4). In this sense, instead of thinking of time as deriving from the succession of movements, Deleuze recognizes the importance of becoming as the only way of accounting for a direct expression of time.

\section{Narrating Time-Images}

12 Such ideas about time and images, I argue, deserve to be put in relation to Don DeLillo's writing in the three books under scrutiny. First of all, DeLillo presents us with a narrative full of pauses and descriptions of characters immersed in their own reflections and visions. This is the time of introspection, which is not just a psychological or a subjective one, but that of an experience overwhelming the self: an absolute time sensed in the activity of contemplation, as in the cases quoted above from The Body Artist and Point Omega. Pauses almost enter the narration as a sort of aberration of time, and these images derive from a coalescence of different and complex temporalities. That's why writing here is mainly thoughtful and meditative ${ }^{6}$, almost lyrical and always dealing with different artistic forms that provide examples of new time schemes.

The Body Artist, for example, clarifies its direct connection with art already from the title. The book is centred on the effort of Lauren (the body artist) to overcome her 
grieving for the loss of her husband Rey Robles-film director and "cinema's poet of lonely places" (2001 27)-who has committed suicide. After this event, Lauren decides to remain in the isolated house the two of them rented for their holidays, and this very house becomes for her a space of memory, a place charged with a time that haunts every room and object. The book opens with an ordinary scene describing the couple having breakfast in an almost half-asleep state of mind, but this picture is abruptly interrupted by the account of Rey's death conveyed in the form of an obituary notice in third person. The reader is told that the subject of his works "is people in landscapes of estrangement," and that "He found a spiritual knife-edge in the poetry of alien places, where extreme situations become inevitable and characters are forced toward lifedefining moments" (29). Such an account of Rey's poetics becomes a sort of preview of what is narrated from there onwards. In what she will call the "days back," Lauren discovers a mysterious presence in a room on the second floor, but the thing doesn't surprise her too much and DeLillo uses here the same adjective which defines the "extreme situations" represented in Rey's movies: "She thought he was inevitable. She felt her way back in time to the earlier indications that there was someone in the house and she arrived at this instant, unerringly, with her perceptions all stored and endorsed" (41).

14 Mr. Tuttle, as Lauren names the visitor, becomes an embodiment and an actualization of all of the past: he imitates the voice of Rey and repeats fragments of the conversations the couple held during their staying in the house. His presence turns into a materialization of memories stored within the place itself, but conceived of as a form of complete otherness: "Maybe this man experiences another kind of reality where he is here and there, before and after [...]. She thought maybe he lived in a kind of time that had no narrative quality" (64-65). Also:

It is a kind of time that is simply and overwhelmingly there, laid out. [...] There is nothing he can do to imagine time existing in reassuring sequence, passing, flowing, happening-the world happens, it has to, we feel it-with names and dates and distinctions. His future is unnamed. It is simultaneous, somehow with present. Neither happens before or after the other and they are equally accessible, perhaps, if only in his mind. (77)

Such simultaneity is also perfectly expressed in Mr. Tuttle's use of verb tenses: "being here has come to me. I am with the moment, I will leave the moment. [...] from the moment I am gone, am left, am leaving. [...] Coming and going I am leaving. I will go and come. Leaving has come to me. [...] Because I am here and where. And I will go or not or never. And I have seen what I will see" (74). Such a strange speech expresses a coalescence of different space-times collapsing onto one another, and also shows the wholeness of time, a sort of pure time displayed by the narration of the single moment.

This "unmeasured time," to follow again Peter Boxall, is "an unbroken continuum" where everything happens simultaneously. ${ }^{7}$ But the very idea of a time without "narrative quality" as expressed by DeLillo himself-a sort of non-linear and nonsuccessive time-also reminds us of Deleuze's words when introducing the opposition between time-image and movement-image, which is based on succession:

The time-image is no longer empirical, nor metaphysical; it is "transcendental" in the sense that Kant gives this word: time is out of joint and presents itself in the pure state. The time-image does not imply the absence of movement (even though it often includes its increased scarcity) but it implies the reversal of the subordination; it is no longer time which is subordinate to movement; it is movement which subordinates itself to time. It is no longer time which derives 
from movement, from its norm and its corrected aberrations; it is movement as false movement, as aberrant movement which now depends on time. (Deleuze, 1997 271)

So, the co-existence of different times embodied in Mr. Tuttle corresponds to the idea of duration as a mass of time, as a virtual time we can access and be accessed by. In fact, if Bergsonian duration as Deleuze understands it is not to be regarded as a subjective time, but rather as time in itself, as the "interiority in which we are" (82), thus this duration ceases to be a personal memory so as to become an autonomous virtuality always present in its potential form, on the verge of taking on a material shape. Moreover, in Deleuze's argument, the connection between actuality and virtuality is granted by the crystal-image, a type of the pure time-image that marks "the point of indiscernibility of two distinct images, the actual and the virtual, while what we see in the crystal is time itself, a bit of time in the pure state" (82). This is exactly the sort of time epitomized by the presence of Mr. Tuttle in the book: a present of the experienced image that is always doubled onto its virtual past and its possible future made accessible at once.

\section{Suspending the Action, Inhabiting Time and Images}

Accordingly, what might be read as a perfect example of time-image in DeLillo's The Body Artist is the scene that closes the book. The narrative describes different times and actions overlapping into a mental visualization that develops in Lauren's mind as well as in the reader's. Any clear distinction between the true and the false, actual and virtual, past and present, blurs at this stage, and the narration focuses on Lauren's altered perception and pre-figurations. As she is driving back home, she imagines and sees herself mounting the stairs, following a strange noise, the chant of Mr. Tuttle that attracts her into the room and, little by little, transforms him into Rey:

She knew how it would happen, driving the car past the NEW USED signs [...]. She'd return home [...], walk along the hall on the second floor, in chanted motion, fitting herself to a body in the process of becoming hers. She could hear him in her chest and throat, speaking hypnotically [...]. His time was here, his measure or dimension or whatever labored phrase you thought to call it [...]. Once she steps into the room, she will already have been there, now, at night, getting undressed. It is a question of fitting herself to the moment. (2001 121)

As the description continues, Rey is now depicted in the same pose as Mr. Tuttle in his first appearance, but the verb tenses are different. In fact, Tuttle "sat on the edge of the bed," in the past tense necessary to the construction of the narrative and the succession of the events, while now Rey "sits on the edge of the bed" (122), placing the event in the present tense of the vision / image in the eyes of Lauren, and in those of the reader. The narrative voice, then, asks: "Are you unable to imagine such a thing even when you see it? [...] Is reality too powerful for you?" (122) Then, as the woman keeps pausing on the threshold of her bedroom on the second floor, overwhelmed by the mass of time accumulated into the house, and projecting the vision of herself into space and time, the narrative proceeds by describing the same actions as the morning in the first chapter, but as if perceived with a delay, almost from a distance: "They are two real bodies in the room. [...] They will already have slept and wakened and gone down to breakfast [...]. But before she stepped into the room, she could feel the look of her face, a frieze of false anticipation" (123). 
outweighed by all that time. When finally she finds the courage to enter:

The bed was empty. She'd known it was empty all along but was only catching up.

[...] She looked into the room and went to the windows. She opened it. She threw the window open. She didn't know why she did this. Then she knew. She wanted to feel the sea tang on her face and the flow of time in her body, to tell her who she was. (124)

Such a description is a sort of temporal circuit where the actual and virtual "coalesce" in the same image, to employ Deleuze's terms. In this final scene, Lauren enters all of time and tries to feel its flow inside herself. In contemplating all of time, she also sees the several possibilities that hadn't previously achieved a full realization.

Moreover, to a certain extent The Body Artist in its entirety might be considered as a pure impression of movement and action. In fact, as DeLillo writes in the opening lines of Chapter 2, describing a scene almost suspended in an extradiegetic moment, "everything is slow and hazy and drained and it all happens around the word seem. All the cars including yours seem to flow in dissociated motion, giving the impression of or presenting the appearance of" (31). However, this sensation endures; and its duration is not related to movement or action, but rather to the nature of time taken as a whole in itself and for itself, exactly as it is for the crystal-image, where we see the "perpetual foundation of time" (Deleuze, 1997 81), which is also the moment when time "comes into being" along with the world. This moment of foundation is not to be understood in terms of succession or chronology, but as an ever-changing flux shaping, simultaneously, both the world and the perception of the world. Furthermore, the "seem" also refers to a perpetual virtuality in the eyes of the reader, as opposed to any actual or precise perception of what is just there, or of what simply is.

The "false movement" implied in the notion of time-image also leads to another important element of Deleuze's philosophy of time, which finds an interesting echo in DeLillo's way of writing about images and time. Again in The Body Artist we find a description of Body Time, a performance by Lauren that literally shows, in an artistic form, the co-presence of multiple times (simultaneously). The artistic piece is a way of revitalizing both the non-narrative time of Mr. Tuttle and the voice of Rey as well as all the different states experienced by Lauren after her husband's death. ${ }^{8}$ In the short chapter titled "Body Art in Extremis: Slow, Spare and Painful," narrated in the style of a magazine account or a review of the performance and "written" by Lauren's friend Mariella Chapman, the reader recognizes all the scenes, images and figures from the previous pages. Lauren herself is described as

acting, always in the process of becoming another or exploring some root identity. [...] Her art in this piece is obscure, slow, difficult and sometimes agonizing. But it is never the grand agony of stately images and sets. It is about you and me. What begins in solitary otherness becomes familiar and even personal. It is about who we are when we are not rehearsing who we are $(2001$ 105, 110).

This constant "becoming-other" enabled by the piece of performance art, and in general epitomized by The Body Artist itself, might be read as a path towards a sort of transcendental condition of the characters, which also reflects a narrative strategy grounded in the presentation of time-images. Instead of providing the reader with a developing story, based on precisely oriented movements, DeLillo's characters, as well as his narrative, accumulate images and perceptions that merge into one another. 
Similarly, a concrete manifestation of stratified time, stretched and visible, experienced in its purest form, is described in Point Omega. The book relates the story of Jim, a student of cinema, who decides to join Elster, a former military strategist, in his house in the desert in order to make a documentary about him. On the one hand, we are thus already in a context evoking and suggesting artistic images, while on the other hand, the isolated setting provides the characters with a particular experience of time, as opposed to that of the city made of "News and Traffic." The altered perception of things in the desert affects the very vision of time itself: "Time slows down when I'm here. Time becomes blind. I feel the landscape more than see it [...]. I never know if a minute has passed or an hour," as Elster says to Jim (2010 24). This time too is "unmeasured," it is perceived on another scale, a sort of transcendental scale: "it's not time passing, mortal time. There is none of the usual terror. It's different here, time is enormous, that's what I feel here, palpably. Time that precedes us and survives us [...]. This is time draining out of our lives" (44-45). In fact, this is pure time: "Time becoming slowly older. Enormously old. [...] This is deep time, epochal time. Our lives receding into the long past. That's what's out there. The Pleistocene desert, the rule of extinction" (72). ${ }^{9}$

21 This time too "has no narrative quality." It doesn't pass but seems to slow down and stop. As for this specific work, an important philosophical reference is already suggested by the title itself. "Point Omega"-or omega point-is a notion expressed by the Jesuit Father Pierre Teilhard de Chardin in the book The Phenomenon of Man (1955), in which the author seems to identify this "point" as the most advanced state of universal evolution, which also coincides with its extinction and self-absorption. According to Teilhard de Chardin, the Omega Point has four main attributes: "autonomy, actuality, irreversibility, and thus finally transcendence" (271). It is interesting to see how all these features also apply to the particular time DeLillo deals with in the novels under analysis. Being autonomous, this point is independent of any space-time limitation, and thus it is all the time in itself (actual and irreversible), yet out of time (transcendent). It ideally represents the openness of time that accumulates and becomes "epochal" as Elster says: a time that simply is. This is the moment when all the individual specificities are re-absorbed into a unique Being, and consciousness looks inward and sees all its possible realizations at once, regardless of any specific subjectivity. ${ }^{10}$

In this sense, the very idea of duration acquires a new status, which is not just a "composition of different memories" but allows the perception of time as it is, as an autonomous and transcendent element. Such a Time, conceived of as a multiplicity perceived in a continuous and unique instant that endures, is also outside the subject, is the same idea of duration that Bergson tries to define in accordance with the notion of a pure and non-subjective time in Duration and Simultaneity:

Thus is born the idea of a duration of the universe, that is to say, of an impersonal consciousness that is the link among all individual consciousnesses, as between these consciousnesses and the rest of nature. Such a consciousness would grasp, in a single, instantaneous perception, multiple events lying at different points in space (Bergson, 1999 31).

Such "impersonal consciousness" is thus time in itself, independent of any subjectivity. DeLillo's characters too always seek transcendence for themselves and disperse into an outward trajectory, as we saw, in order to create a new awareness from a different viewpoint than their own. 
The narrative structure reflects this fragmented dimension with a strategy that could be read in the wake of Deleuze's notions of interstice, which is connected to the idea of becoming. With this concept Deleuze identifies something outside any narrative form which doesn't strictly belong to images, but rather activates a resonance through different parts. Such interstice may be conceived of as a "method of vision," an outward tension arising from the act of perceiving the "whole [that] is the outside." In Deleuze's terms, "when the whole becomes the power of the outside which passes into the interstice, then it is the direct presentation of time, or the continuity which is reconciled with the sequence of irrational points, according to non-chronological time relationships" (Deleuze, 1997 181). This is perception in itself, a suspended gaze without a subject, exactly like that shown in the opening lines of The Body Artist. Moreover, such interstice brings into play otherness and alterity: it is an outside that becomes an impersonal perception where everything is simultaneous in time, beyond any simple this / that opposition. The interstice also allows for the co-existence of different temporalities and produces what Deleuze calls "undecidable alternatives" between times.

\section{Visualizing and Narrating Otherness in the Interstice}

As seen above, from a structural point of view, the different parts in which the narrative of The Body Artist is divided already show some recurrent elements and overlapping visions. Such a narrative organization also seems to put into play what Karim Daanoune identified as a chiasmus pattern while discussing DeLillo's way of presenting a space of indeterminacy through his writing, a space of dynamic interaction between the elements represented and described. In Daanoune's words, in fact, this chiastic mechanism shows "patterns of circulation and exchange" that the reader must follow (217). We already saw how in The Body Artist's last scene such a recurrent and somehow repetitive structure is peculiar and reorganizes the entire book and its time into an overlapping dynamic. As for the specific idea of interstice, these spaces in the narrative tissue are themselves places where the entire narrative is reorganized and time and images intertwine. In this sense, still in The Body Artist the short obituary placed after the first chapter, as well as the account of Lauren's performance of Body Time, are just two examples of what might be regarded as an interstice, where the main succession of the events is suspended and the narrative voice undergoes a differentiation with respect to the rest of the book. At the same time, the separated lines that introduce Chapters One, Two, Six and Seven describe pure acts of perception where reality and virtuality fuse into an undecidable or indeterminate vision: "the dead squirrel you see in the driveway, dead and decapitated, turns out to be a strip of curled burlap, but you look at it, you walk past it, even so, with a mixed tinge of terror and pity" (2001 111). Mr. Tuttle himself materializes a sort of in-between space-time, and thus might be regarded as an interval or a sort of interstice. In this case too, DeLillo's narrative provides this interval with substance, a body-the materiality of Mr. Tuttle's body-and also the material substance of his words, of his language, that manifests a multi-layered time. He embodies a sort of suspension where the past (Ray's words) and the future (Lauren's performance) reorganize and expand again in different directions. 
25 An even more powerful example of interstice is expressed by the structure of Point Omega. The book is introduced and closed by two almost independent sections, Anonymity 1 and 2, functioning as the story's prologue and epilogue. Here, DeLillo introduces a pure otherness, an outer perspective where chronological succession gives way to a constant becoming-other of the narrative voice as well as of the scene described. These parts present an anonymous character watching the video-installation 24H Psycho by Douglas Gordon, a version of Alfred Hitchcock's famous Psycho that slows down the original movie to a frame rate of two frames per second in order to make it last twenty-four hours. The writing tries to get into the images, and reflects on the way time and the slowness of the video frames affect the observer's perception. Moreover, such a description becomes a sort of programmatic part that establishes a rhythm to read the rest of the book. The anonymous character also projects his memories and visions onto the frames of the video, by anticipating the moments he is actually watching. The "submicroscopic moments" in Gordon's movie are thus expanded by the narration and they become a space for the multiplication of different times. The description of this "unbearable time" equally presents the reader with an estranged perception that coincides with that of the observer: "What he was watching seemed pure film, pure time. The broad horror of the old gothic movie was subsumed in time. How long would he have to stand here, how many weeks or months, before the film's time scheme absorbed his own, or had this already begun to happen?" (2010 6)

And that "time scheme" also modifies the perception of reality: "This film had the same relationship to the original movie that the original movie had to real lived experience. This was the departure from the departure. The original movie was fiction, this was real" (13). In Anonymity 2, the ending part of Point Omega, the same anonymous observer himself is described as approaching the point of indiscernibility between him and the image projected on the screen: he "waits to be assimilated, pore by pore, to dissolve into the figure of Norman Bates, who will come into the house and walk up the stairs in subliminal time" (116). This is the same time scheme that we find in the desert, the same vanishing point (or point omega) described by Elster: the epochal time that stretches before the eyes and allows for moments of absolute absorption into the outside and into time itself. And this is also the same time scheme that absorbs Elster's daughter who at one point joined the two men in the house and disappears mysteriously, as if dispersed into the desert and its epochal time.

Another "out-of-joint" temporality can finally be found in Zero $K$, the story of the billionaire Ross Lockhart who convinces his sick wife, Artis, to undergo a process of cryoconservation. In his trips to the city of Chelyabinsk, where the cryoconservation centre Convergence-once again a point of fusion and confusion, an interstice in itselfis based, Ross is accompanied by his son Jeffrey, the book's narrator. A meditation about time here is already clear from the titles of the three parts into which the book is divided. The first one, In the Time of Chelyabinsk, contains some descriptions of the time spent at Convergence while Artis is psychologically and physically prepared for the operation. The ambience is an artificial setting designed to give the impression of a suspended and isolated-almost unreal-space-time where differences between images and reality, truth and falsehood, constantly blur and converge. In the building there are screens that descend from the ceiling and display images of natural disasters, death, dangers and masses of people moving. When these technological devices appear the 
narration stops, and focuses on descriptions of the images themselves on the verge of becoming real:

I had to pause now, stop and look, because the screen in the ceiling began to lower and a series of images filled the width of the hallway. People running, crowds of running men and women, they're closely packed and showing desperation dozens, then hundreds [...]. Here they come, mouths open, arms pumping, headbands, visors [...]. (2016 152)

The narrator is tempted to consider them as "visual fictions" or "digital code, all of it computer-generated, none of it real" (152). But then something mysterious happens as those images actualize into a real event:

I watched until the images faded and the screen began to lift [...]. I'd gone only a short way along the hall when there was a noise, hard to identify and rapidly getting louder. I went a few more paces and had to stop, the noise nearly upon me, and then they came wheeling around the corner charging in my direction, the running men and women, images bodied out, spilled from the screen. (2016 152-153)

As for the third and last part, In the Time of Kostantinovka, it describes the life of Jeffrey and his difficult relationship with his girlfriend Elen and her adopted son Stak, who eventually is killed in the Ukrainian civil war, while images of his death are screened in real time (263) and watched by Jeffrey himself during his second trip to Convergence. In this part, Ross too decides to embrace the process of cryoconservation in order to survive eternally in a condition where "[t]ime is multiple, time is simultaneous. This moment happens, has happened, will happen" (244-245).

However, it is the central part, titled Artis Martineau, that is the most interesting for the analysis proposed in this article. The short chapter reports the thoughts of the cryogenized woman and presents a monologue where her first-person voice is intertwined with third-person descriptions of her condition. This is "voice in its barest sheddings," disembodied, experiencing a collapsing of time similar to that of Mr. Tuttle: "But am I who I was"; "She is able to say what she feels and she is also the person who stands outside the feelings"; "She is first person and third person with no way to join them together"; "I can feel time. I am all time [...]. Minutes, hours, days and years. Or is everything she knows contained in one timeless second" (157-159). This too is a suspended time without any relation to personal subjectivity, because what remains of her is just the perceptual activity unanchored from any possible conscious development. It is pure perception, pure time and thoughts suspended in the void. Moreover, this middle section of the book represents a totally outer perspective that works as an interstice reorganizing the entire reading in terms of a recombination of images in ever new forms, towards a pure becoming other-than-subjectivity of time.

In this bare image DeLillo presents us with an absolute and objective time materialized by an immobile body. This is the same time as perceived by characters at Convergence, made of visions, memories, and imaginings. The real world, by contrast, is represented through images of terror and destruction broadcast on screens located in the corridors. These images are charged with different times and events happening outside the closed and aseptic ambience of Convergence, as well as outside the concentrated and suspended world and time of the characters. 


\section{Entering the Whole Time}

In all the passages mentioned above, time is crystallized and assumes different forms, through images and sections separated from each other in the text. These are pieces where time is described as expanding and contracting, and where the "tone" of the narrative voice changes continuously. New modalities of concatenation between images are shown, presenting the reader with a non-subjective time. This is exactly the crucial point of the concept of interstice, according to Deleuze, a "spacing" that stops the continuity of images and introduces a blank where the perception of time structure is reorganized.

But what kind of relation between time, narration and images emerges from the examples taken from DeLillo's writing? First of all, it is worth noting that in his writing DeLillo doesn't deal with time and images in abstract or simply thematic terms. On the contrary, he tries to make them visible and perceivable to the reader by using narrative images and descriptions of characters intent on the activity of perceiving the flow of time itself. That's why we may think of the examples analyzed here as a way of imagining time directly-that is, giving time a figure, a consistency outside a simple and tranquil recollection of the past. Thus, an interesting consequence is that time is not only internalized into a specific psychology or within the memories of a particular character, but rather it is considered as a whole, detached from any subject. Time is objectified, is a form of "outside," as Deleuze would say. So, DeLillo's writing of time desubjectifies memories and gives them independent substance and bodies-as in the case of The Body Artist or of the chapter "Artis Martineau"-as well as making it concrete in external images interfering with an inner time, as in the cases of Point Omega and the other parts of Zero K. Time is thus shown and written in its totality, as it happens with the notion of time-images. In this way, DeLillo's writing describes different modalities where specific durations, particular images and several narrative fragments recombine and concatenate simultaneously in order to give shape to an objective time perceived and accessed through images. To this extent, DeLillo's writing is not just a way of talking about time in a narrative form, but rather it is a way of writing time-a sort of chronography where different temporalities are imagined as coexisting simultaneously. The suspension of narrative time is thus a strategy to create an interstice, a space, where other times, lives and identities can be re-organized and defined by their specific otherness. This way of dealing with time as a non-subjective experience allows for the opening of a space where infinite narrative possibilities can coexist together in a meaningful and always novel way.

\section{BIBLIOGRAPHY}

BOXALL, Peter. Don DeLillo. The Possibility of Fiction. London: Routledge, 2006.

BOXALL, Peter. "DeLillo and Media Culture." The Cambridge Companion to Don DeLillo. Ed. John N. Duvall. Cambridge: Cambridge University Press, 2008, p. 43-53. 
BERGSON, Henri. Time and Free Will. 1889. Translated from the French by F.L. Pogson. Mineola, New York: Dover Publications, 2001.

BERGSON, Henri. Matter and Memory. 1896. Translated from the French by N.M. Paul and W.S. Palmer. New York: Cosimo, 2007.

BERGSON, Henri. Duration and Simultaneity. 1922. Ed. Robin Durie. Translated from the French by L. Jacobson. Manchester: Clinamen Press, 1999.

COWART, David. The Physics of Language. Athens: University of Georgia Press, 2002.

COWART, David. “The Lady Vanishes: Don DeLillo's Point Omega.” Contemporary Literature, vol. 53, no. 2, 2012, p. 31-50.

DAANOUNE, Karim. “'The Rough Shape of a Cross': Chiastic Events in Don DeLillo's 'Baader Meinhof."' Don DeLillo After the Millennium. Ed. Jacqueline A. Zubeck. New York: Lexington Books, 2017.

DELEUZE, Gilles. Bergsonism. 1966. Translated from the French by H. Tomlinson and B. Habberjam. New York: Zone Books, 1991.

DELEUZE, Gilles. Cimema 1: The Movement-Image. 1983. Translated from the French by H. Tomlinson. Minneapolis: University of Minnesota, 1986.

DELEUZE, Gilles. Cinema 2: The Time-Image. 1985. Translated from the French by H. Tomlinson and R. Galeta. Minneapolis: University of Minnesota, 1997.

DELEUZE, Gilles. Negotiations. 1990. Translated from the French by Martin Joughin. New York: Columbia University Press, 1995.

DELILLO, Don. “The Power of History.” New York Times Magazine, Sept. 7, 1997.

DELILLO, Don. The Body Artist. London: Picador, 2001.

DELILLO, Don. Cosmopolis. London: Picador, 2003.

DELILLO, Don. Point Omega. London: Picador, 2010.

DELILLO, Don. Zero K. New York: Scribner, 2016.

DEWEY, Joseph. Beyond Grief and Nothing. Columbia: University of South Carolina, 2006.

GENETTE, Gerard. Narrative Discourse. An Essay in Method. 1972. Translated from the French by J.E. Lewin. New York: Cornell University, 1980.

LENTRICCHIA, Frank. “Libra as Postmodern Critique.” Introducing Don DeLillo. Durham: Duke University Press, 1991.

MCGRATH, Charles. "Don DeLillo, a Writer by Accident Whose Course Is Deliberate." New York Times, 3 Feb. 2010.

PITOZZI, Andrea. “Abitare il tempo, abitare il corpo. Una lettura di The Body Artist di Don DeLillo.” Elephant \& Castle, vol. 11, 2015, p. 5-29.

TEILHARD DE CHARDIN, Pierre. The Phenomenon of Man.1955. Translated from the French by B. Wall. New York: Harper, 1959.

TRÉGUER, Florian. "Vers une image symptomatique : Don DeLillo et la crise de l'évidence." Revue française d'études américaines, vol. 89, no. 3, 2001, p. 98-112.

VEGGIAN, Henry. Understanding Don DeLillo. Columbia: University of South Carolina, 2015. 


\section{NOTES}

1. For an inquiry into the tension and frictions between high culture and popular culture in DeLillo's first novels, see Peter Boxall's "DeLillo and Media Culture" in Duvall. On the importance of fiction as a means to build counter-narratives and alternative counter-histories starting from iconic pictures and images, see DeLillo's fundamental essay "The Power of History."

2. Florian Tréguer talks about a "symptomatic image" and the complex way DeLillo's writing deals with notions like image, reproduction and repetition in "Vers une image symptomatique: Don DeLillo et la crise de l'évidence."

3. In this regard, see, in particular, Frank Lentricchia's "Libra as Postmodern Critique."

4. DeLillo himself says that his most recent novels "are more philosophical, for better or worse, and more interested in the subject of time," as reported by Charles McGrath in his New York Times article.

5. According to the scheme presented by Genette, narrative duration derives from the interaction between story time and narrative time, namely between the events narrated and the narration itself (Genette 33).

6. In the analysis devoted to Valparaiso, The Body Artist, Cosmopolis and Love-Lies-Bleeding in his Beyond Grief and Nothing. A Reading of Don DeLillo, Joseph Dewey considers these works as "Zen-like parables that can frustrate reader involvement, appearing at times to be gnomic meditations rather than traditional narratives" (Dewey 128).

7. With reference to time as presented in DeLillo's recent works, Peter Boxall also talks of an "evacuated moment [that] does not only eject one from time, but also abandons one to it, to a time whose sinewy dimension lies naked and exposed" (2006 217).

8. Again Peter Boxall describes Body Time as taking place in a "temporality that is unframed, a kind of time that is all time-past, present and future-and no time at all. [...] A time that is so unboundaried and so fleeting that it moves in the slowest possible motion" (2006 221).

9. Such idea of "extinction" also finds a counterpoint in the sudden and mysterious disappearance of Jessie, Elster's daughter, who seems to be absorbed by the desert itself and its enormous time.

10. Elster himself describes the omega point as a point where "consciousness accumulates. It begins to reflect about itself" (2010 72).

\section{ABSTRACTS}

This article focuses on the most recent writings of Don DeLillo, and in particular it analyzes three of DeLillo's later works, namely The Body Artist, Point Omega and Zero K, as examples of a more meditative and reflective attitude towards the themes of time and image in his recent production. By studying how these books present the reader with a sort of suspended narrative time, I will read them in the light of concepts and notions drawn from the philosophy of Henri Bergson and Gilles Deleuze, in particular Bergsonian duration and Deleuze's idea of the time-image. Reading DeLillo's recent novels according to this philosophical framework enables one to consider the implications his writing draws between time and images in configuring the perception of time as an almost physical, substantial and non-subjective whole to be sensed and described through narrative and figurative strategies. 
Cet article propose une lecture de la production la plus récente de Don DeLillo et, en particulier, vise l'analyse de trois romans, The Body Artist, Point Omega et Zero K, ces livres représentant, par rapport à la production précédente de l'écrivain, des exemples d'une attitude plus réflexive et méditative à l'égard de sujets comme le temps et l'image. En analysant la manière dont ces ouvrages présentent une sorte de suspension du temps narratif, on tracera une connexion entre les descriptions de moments et de scènes plus contemplatifs et certains concepts dérivés des philosophies d'Henri Bergson et de Gilles Deleuze, notamment l'idée de durée bergsonienne et la notion deleuzienne d'Image-Temps. L'étude de ces trois romans de DeLillo dans un tel cadre philosophique permet de considérer toutes les implications que l'écriture trace entre le temps et l'image, en configurant et exprimant une perception du temps comme totalité physique, sensible et non-subjective, qui est perçue et décrite à travers des stratégies narratives et de figuration.

INDEX

Keywords: time, image, Deleuze (Gilles), Bergson (Henri), duration, time-image, narration Mots-clés: temps, image, Deleuze (Gilles), Bergson (Henri), durée, image-temps, narration

\section{AUTHOR}

\section{ANDREA PITOZZI}

Università degli Studi di Bergamo 